Article

\title{
Evaluation of Stress and Fatigue of a Rail Vehicle Suspension Component
}

\author{
Michał Opala ${ }^{1, *(\mathbb{D}}$, Jarosław Korzeb ${ }^{1} \mathbb{(}$, Seweryn Koziak ${ }^{1, *(\mathbb{D})}$ and Rafał Melnik ${ }^{2} \mathbb{D}$ \\ 1 Faculty of Transport, Warsaw University of Technology, Koszykowa 75, 00-662 Warsaw, Poland; \\ jaroslaw.korzeb@pw.edu.pl \\ 2 Faculty of Computer Science and Food Science, Lomza State University of Applied Sciences, Akademicka 1, \\ 18-400 Łomża, Poland; rmelnik@pwsip.edu.pl \\ * Correspondence: michal.opala@pw.edu.pl (M.O.); seweryn.koziak@pw.edu.pl (S.K.)
}

Citation: Opala, M.; Korzeb, J.; Koziak, S.; Melnik, R. Evaluation of Stress and Fatigue of a Rail Vehicle Suspension Component. Energies 2021, 14, 3410. https://doi.org/ $10.3390 /$ en14123410

Academic Editor: João Pombo

Received: 11 May 2021

Accepted: 4 June 2021

Published: 9 June 2021

Publisher's Note: MDPI stays neutral with regard to jurisdictional claims in published maps and institutional affiliations.

Copyright: (c) 2021 by the authors. Licensee MDPI, Basel, Switzerland. This article is an open access article distributed under the terms and conditions of the Creative Commons Attribution (CC BY) license (https:// creativecommons.org/licenses/by/ $4.0 /)$.

\begin{abstract}
The article discusses the use of pivot bearing friction liners, made of selected materials, in railway freight wagons' spherical centre bowls. Comparative studies on the effect of suspension dynamics on the equivalent stresses in the liner material were carried out using the finite element method and multibody simulation. The results show the magnitude and location of the highest stresses in the liner with varying input loads, friction coefficients and interacting materials. The analysis is a basis for a simulation method for predicting the fatigue life of the suspension friction liner placed in the centre bowl between the bogie frame and the vehicle body.
\end{abstract}

Keywords: fatigue life prediction; railway freight wagon; simulation studies

\section{Introduction}

Over the last decades, freight wagon operators have started to use a wide range of non-metallic friction liners made of various materials such as polymeric materials with modifying agents or resin-based composites. Such non-metallic liners offer several advantages over metal surface interaction such as ease of installation, lower coefficient of friction and reduced wear. However, they also have some disadvantages, which include a higher susceptibility to damage. Depending on the specific material, such negative phenomena manifest in the form of permanent deformations below the yield point (cold flow) during higher compressive loads, increased susceptibility to friction property change at low temperatures, low resistance to high temperatures in terms of wear and mechanical properties [1-3], creating an electrical insulation of the vehicle body, which leads to the accumulation of electric charge. The mechanical properties of polymers are also affected by pressure, however, there has been limited research into this topic in recent years [4,5]. Experiments on the mechanical behaviour of polymers under hydrostatic pressure show that increasing hydrostatic pressure results in increased modulus and yield stress, sometimes by as much as $50-100 \%[1,4,5]$. Other properties such as glass transition, could also be pressure-dependent and specific to the polymeric material. Different yield criteria are used to describe the yield behaviour in polymers, the common part of the criteria suggest linear dependence of the yield stress as a function of hydrostatic pressure. In engineering practice the yield criterion for polymers often uses the modified Huber-Mises-Hencky yield function [1]:

$$
\left(\sigma_{1}-\sigma_{2}\right)^{2}+\left(\sigma_{2}-\sigma_{3}\right)^{2}+\left(\sigma_{3}-\sigma_{1}\right)^{2}=2 \sigma_{f}^{2}\left(1+\frac{\beta p}{K}\right)^{2}
$$

where $K$ is the bulk modulus of the polymer, $\beta$ is a numerical coefficient that characterizes the pressure dependence of the flow strength and pressure $p$ is defined by:

$$
p=-\frac{1}{3}\left(\sigma_{1}+\sigma_{2}+\sigma_{3}\right)
$$


For polymers, the strength $\sigma_{f}$ is identified as the stress at which the stress-strain curve becomes markedly non-linear. However, in the studied case, the pressure order of magnitude is considered to have a negligible influence on the yield behavior. On the other hand, most damage occurring in structural elements subjected to cyclic loading is caused by fatigue. The unfavourable operating conditions of such elements may contribute to an unforeseen shortening of their operational time and, as a consequence, to a more serious failure. In the case of a freight wagon, damage to the friction lining in the centre bowl due to excessive wear and tear of the material (Figure 1) leads to a reduction in the clearance between the bogie and the wagon body. Because of the reduced clearance, the vehicle body can come to direct contact with the steel part of the bogie and the vertical forces increase where the side slides of secondary suspension are located, which leads to a significant increase in the resistance torque of the bogie (by approximately two or more times). As a consequence, such deviations of vehicle suspension parameters may lead to the violent vibration of vehicle suspension that can not only affect running safety [6], but also deteriorate the vehicle-infrastructure interaction performance [7]. Thus it is necessary to ensure a good performance and reliability of the suspension.

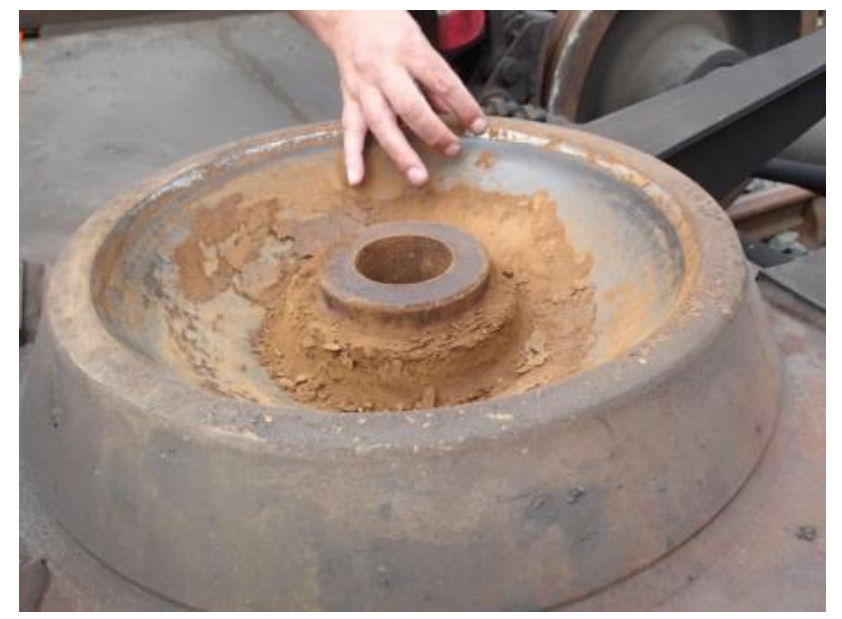

Figure 1. View of worn friction liner in the center bowl. Adapted from [8].

The purpose of the wagon center bowl friction lining is to maintain constant friction conditions during the relative rotational movement between the chassis and the bogie. The friction conditions depend mainly on the type of liner material and the admixtures used, as well as on the presence of any contamination and damage.

Testing of the friction liner as a typical part of a railway vehicle is covered by the general requirements set out in the regulations $[9,10]$. The scope of pre-admission tests should include the following aspects:

- $\quad$ Checking the conformity of the performance with the technical requirements of manufacturing and acceptance, technical documentation and the requirements set out in the relevant national or European standards for railway vehicles, their assemblies, subassemblies and components;

- Checking the quality certificates, attestations, results of quality and technical acceptance for the assemblies, subassemblies, elements and materials used;

- Checking the quality of the surface condition;

- Measurement of the torsional (resistance) moment of the bogie for the empty wagon in the new condition and for the empty and loaded wagon after 6 months of operation;

- Measurement of liner wear (surface geometry) after completing the test run;

- Attempts to run the wagon.

In practice, conducted research is based on the provisions set out in the UIC 5101 [11], EN 14363 [12] and Technical Specifications for Interoperability Freight Wagons (TSI WAG) [13]. General design requirements are described in the document ERRI [14]. 
In this work, simulation study has been carried out on the influence of the suspension dynamics on the level of multiaxial stresses in the material of the friction pair in the connection between the body and bogie of the freight wagon, taking into account the friction conditions in the contact area.

\section{Selection of Model Parameters}

\subsection{Centre Bowl Materials and Modeling}

The interactions in the area of contacting surfaces of the centre bowl were determined using the finite element mesh model. The interactions in the area of contacting surfaces of the centre bowl were determined using the finite element mesh model. The FEM method assumes that the range of deformation of the liner material is below $5-10 \%$ and the linear elastic characteristic is sufficiently accurate in this regard to describe this material. The FEM mesh consists of 54,158 nodes, while the contact area itself contains 1089 pairs of nodes (Figure 2). To calculate the friction torque the APDL scripting language of Ansys Mechanical was used.
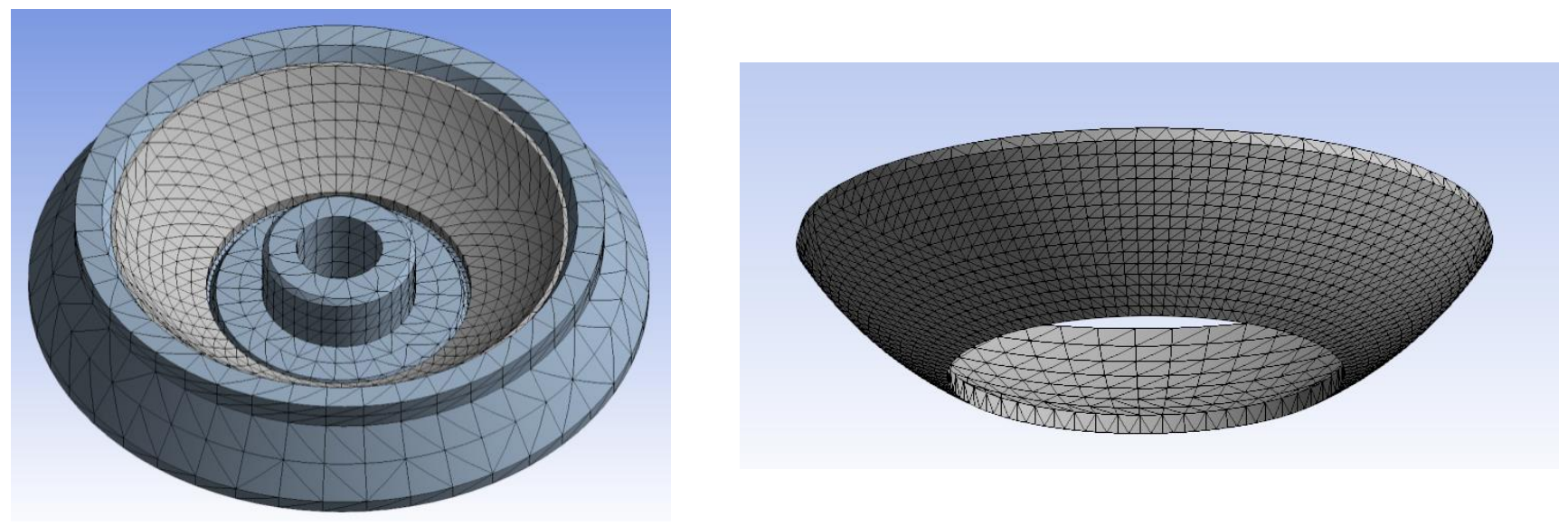

Figure 2. Mesh of the FEM model of centre bowl with friction liner.

In the calculations, three types of friction pair materials were considered, i.e., steel, polymer lining and one of the Fe-enriched or non-ferrous metal alloys. The selected materials are widely available, relatively cheap and often used in the industry, at the same time there are large differences between them in terms of the material constants and mechanical characteristics that describe them. Efforts were directed to investigate the behavior of these materials in terms of possible deformations and stresses and their impact on fatigue life, taking into account their specific use as an element of rail vehicle suspension exposed to significant loads. Material constants are presented in Table 1.

When choosing a metal alloy, two types of bronze BA1032, B101 and one brass MA58 were considered. Bronze BA1032 $\left(\mathrm{CuAl}_{10} \mathrm{Fe}_{3} \mathrm{Mn}_{2}\right)$ is aluminum-iron-manganese bronze. It is characterized by high hardness $(120 \mathrm{HB})$ and has high resistance to corrosion and high durability to static and variable loads, including impact loads, and also has very good abrasion resistance. Due to its properties and resistance to elevated temperatures, it can be used to produce heavily loaded machine parts exposed to corrosion and abrasion under simultaneous mechanical stress, e.g., sliding bearings.

In a situation where higher sliding parameters are important, the use of $\mathrm{B} 101\left(\mathrm{CuSn}{ }_{10} \mathrm{P}\right)$ tin-phosphor bronze must be considered. It is characterized by a lower hardness than BA1032-on the order of $90 \mathrm{HB}$. It also has high corrosion resistance as its predecessor, but the addition of phosphorus improves abrasion resistance while exhibiting self-lubricating properties. As with the previous bronze, this one is also resistant to high mechanical loads, hence similar use-in heavily loaded machine parts, high-speed and poorly lubricated parts of slide bearings. As steel products, bronzes BA1032 and B101 are produced, inter alia, in the form of finished sleeves and as final castings. Bronze BA1032 is cheaper than 
B101. As an additional material, MO58 brass $\left(\mathrm{CuZn}_{40} \mathrm{~Pb}_{2}\right)$ was considered. This copper alloy displays plastic properties, it can be machined, as well as plastically formed and forged. From the point of view of the structural analysis, the key material constants of the mentioned metal alloys are only slightly different. For the simulation purpose, material constants for bronze BA1032 were selected.

Table 1. Material constants.

\begin{tabular}{|c|c|c|c|c|c|}
\hline Material Constant & $\begin{array}{l}\text { Material } \\
1-\text { Steel }\end{array}$ & $\begin{array}{c}\text { Material } \\
\text { 2-Polymer Liner }\end{array}$ & $\begin{array}{c}\text { Material } \\
\text { 3-Bronze B101 }\end{array}$ & $\begin{array}{c}\text { Material } \\
\text { 4-Bronze B1032 }\end{array}$ & $\begin{array}{c}\text { Material } \\
\text { 5-Brass MA58 }\end{array}$ \\
\hline Density $\left(\mathrm{kg} \mathrm{m}^{-3}\right)$ & 7850 & 1146 & 8800 & 7500 & 8430 \\
\hline $\begin{array}{l}\text { Modulus of elasticity } \\
\text { (tangent) (MPa) }\end{array}$ & 200,000 & 3400 & 103,000 & 115,000 & 110,000 \\
\hline $\begin{array}{l}\text { Compressive modulus of } \\
\text { elasticity (MPa) }\end{array}$ & 200,000 & 2290 & 103,000 & 115,000 & 110,000 \\
\hline Poisson's ratio $(-)$ & 0.3 & 0.4 & 0.33 & 0.3 & 0.33 \\
\hline Bulk modulus (MPa) & 166,670 & 3816 & 101,000 & 113,000 & 108,000 \\
\hline Shear modulus (MPa) & 76,923 & 817 & 39,000 & 44,000 & 42,000 \\
\hline Yield point $(\mathrm{MPa})$ & 250 & 66 & 110 & 200 & 170 \\
\hline Compressive strength (MPa) & 250 & 99 & 100 & 190 & 160 \\
\hline $\begin{array}{l}\text { Nominal coefficient of dry } \\
\text { friction in contact of } \\
\text { material with steel }(-)\end{array}$ & $0.25-0.4$ & $0.1-0.25$ & $0.25-0.35$ & 0.24 & $0.3-0.35$ \\
\hline
\end{tabular}

One of the basic functions of the centre bowl friction liner is to maintain constant friction conditions during the relative rotational movement between the chassis and the bogie. The value of the nominal friction torque is a compromise between the requirements for vehicle stability and the properties of negotiating a curved track with a small radius of curvature $[15,16]$.

The magnitude of the frictional moment in a friction ball joint can be determined from the equation:

$$
M=\int_{\theta_{0}}^{\theta_{1}} R \sin (\theta) \mu d N
$$

where $\mu$-friction coef., $R$-curvature radius, $\theta$-the angle of inclination of the radius of curvature with respect to the vertical axis, $d N$-differential of normal force on the interface in the form:

$$
d N=\sigma(\theta) 2 \pi R \sin (\theta) d \theta
$$

where: $\sigma$-contact pressure function. Finally, the magnitude of the frictional moment at a given load can be represented as:

$$
M=f \mu N
$$

where $f$-shape factor in a given conformal connection, $N$-normal force.

The shape factor $f$ in Equation (5) can be determined by various methods. The value of this factor obtained numerically using FEM is on average $f=0.09$ (polymer-steel) and $f=0.11$ (steel-steel). In analytical solutions based on Hertz's theory, the obtained values are slightly higher, the range of these values is $f=0.12-0.17$.

To determine the coefficient of $f$, one had to find the distribution of contact pressure between interacting surfaces using the FEM model, which was built in the Ansys program. This model takes into account the presence of conformal contact in the presence of friction. Next, the moment of friction was determined, adding to each element of the contact surface the appropriate products of the distance from the axis of rotation, the elemental normal force acting on each element and the set coefficient of friction. The factor $f$ was determined using the transformation of Equation (5). The results obtained from the FEM model were verified on the basis of measurements made on the test bench for the resistance of the 
bogie (Figure 3), the test procedure is described, among others, in EN 143633 as one of the methods of testing safety against derailment. The angle of rotation of the bogie is determined from the dependence:

$$
\varphi=\frac{2 a^{*}}{R}+\frac{0.020}{2 a^{+}}(\mathrm{rad})
$$

where: $2 a^{*}$ —distance between the pivots, $2 a^{+}$-spacing of wheelsets in the bogie, $R$-the minimum radius of the curve which the wagon can pass. The measurement is performed for the wagon in the empty and loaded condition at the rotational speed of $1.0^{\circ} / \mathrm{s}$ or less [11].

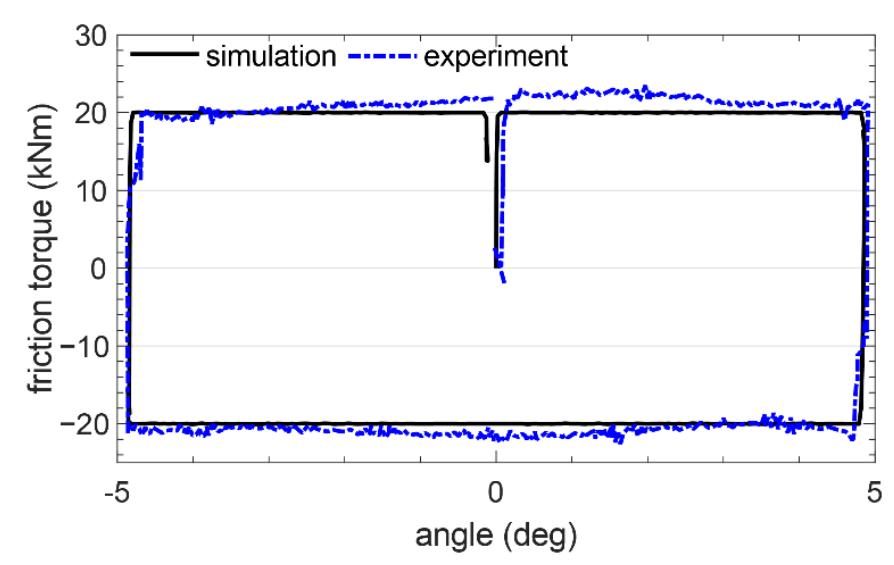

(a)

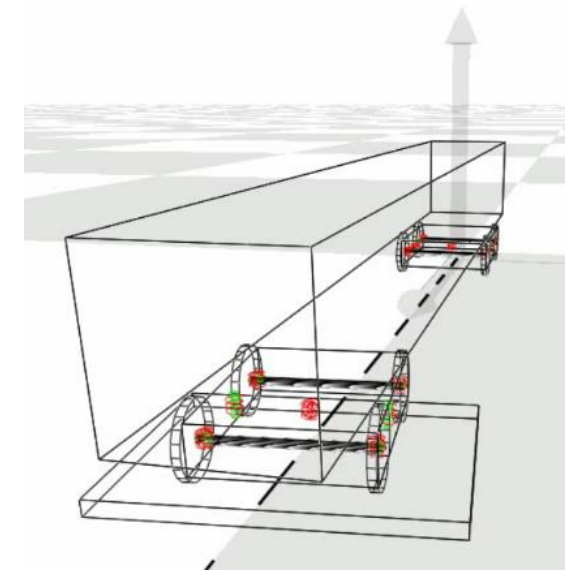

(b)

Figure 3. (a) An example of characteristics of the friction torque between the boogie and the loaded wagon body as a function of the angle of bogie rotation with respect to the vertical axis (measuring angular speed $\left.\omega=1^{\circ} / \mathrm{s}\right)(\mathbf{b})$ View of the vehicle model during rotation of the bogie.

In order to validate the models and verify the results, a bench test for the resisting torque of the bogie was mapped. A multibody model of a freight wagon with 30 degrees of freedom was built, in which the relevant vehicle elements in the form of rigid bodies are connected by means of elastic and damping elements, including friction pairs with dry friction between bogies and the body. Parameters of friction pairs were adopted on the basis of calculations obtained from the FEM model, the LuGre model was used to describe dry friction in the vehicle suspension [17].

\subsection{Vehicle Model}

The freight wagon model in the form of a multibody system was built on the basis of technical data of the Eaos-type wagon equipped with Y25 (25TN) bogies. This wagon is intended for the transport of loose goods such as coal, sand, ore, aggregate, as well as for the transport of concentrated cargoes not sensitive to atmospheric impact. Pursuant to the design purpose, the vehicle equipped with Y25Lsd or Y25Lsd1 bogies can move with loads up to 20 tons per axle and 22.5 tons per axle with maximum operating speeds of $120 \mathrm{~km} / \mathrm{h}$ and $100 \mathrm{~km} / \mathrm{h}$ respectively.

The wagon body is placed on bogies via central pivots with friction lining, which carries $70 \%$ of the wagon's weight. The remaining $30 \%$ of the wagon's weight is transferred by elastic side bearers, which also have friction elements (Figure 4). The side bearers are in permanent contact with the body of the vehicle and the spring element of the bearer has a preload. 


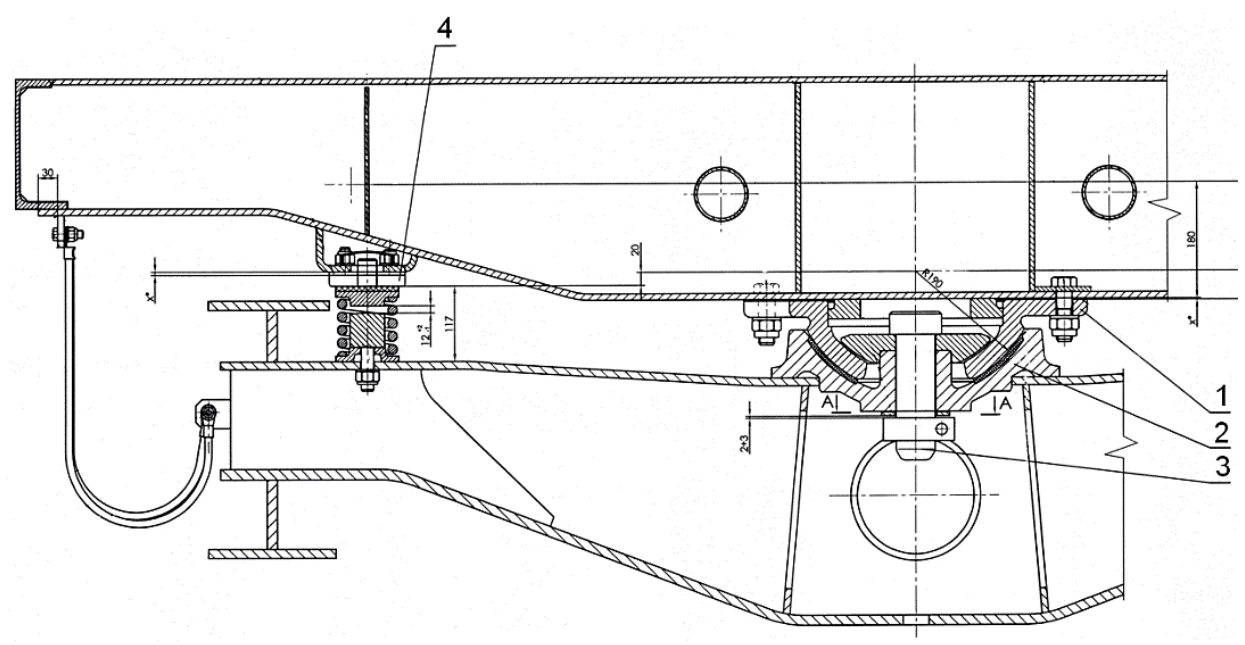

Figure 4. Connection between the body and the bogie frame of the railway freight vehicle. 1-pivot, 2-centre bowl, 3-pivot pin, 4-slide bearer, source: based on technical documentation.

The model of the vehicle is implemented in the proprietary computer simulation program 'Simdel' in the form of a system of rigid bodies connected with springs and dampers of linear and non-linear characteristics. Equations of motion are generated automatically by the multibody numerical algorithm using the Newton-Euler formalism for any given structure of the system. The system of rigid bodies interacts with the track through the wheels and rails profiles which are provided in the form of coordinates measured on real S1002/UIC60 profiles.

The model of tangential contact interactions is based on Kalker's simplified theory and the FASTSIM algorithm. The model of normal contact interactions is based on the multi-elliptic contact patch geometry calculated using Hertz theory and using equivalent contact shape formed by two ellipses. The relative rigid slip between the points on the wheels and rails in the contact zone is calculated using $3 \mathrm{D}$ geometry and kinematic data of the rotational and translational velocities related to the reference frame moving along the track line with a constant speed. Table 2 lists the most important mass and inertia parameters, while Table 3 shows the suspension parameters used in the model.

Table 2. Inertia parameters of the vehicle model. Reprinted from [17].

\begin{tabular}{|c|c|c|c|c|}
\hline Body & Mass (kg) & $\begin{array}{l}\text { Roll Inertia } \\
\left(\mathrm{kg} \cdot \mathrm{m}^{2}\right)\end{array}$ & $\begin{array}{l}\text { Pitch Inertia } \\
\quad\left(\mathrm{kg} \cdot \mathrm{m}^{2}\right)\end{array}$ & $\begin{array}{c}\text { Yaw Inertia } \\
\left(\mathrm{kg} \cdot \mathrm{m}^{2}\right)\end{array}$ \\
\hline Carbody & 70,000 & 59,383 & 928,320 & 953,980 \\
\hline Bogie frame & 2070 & 1400 & 2100 & 2400 \\
\hline Wheelset & 2000 & 1200 & 200 & 1200 \\
\hline
\end{tabular}

Table 3. Primary suspensions characteristics Reprinted from [17].

\begin{tabular}{cccc}
\hline Suspensions & Longitudinal (kN/m) & Lateral (kN/m) & Vertical (kN/m) \\
\hline Primary & 4000 & 4500 & 3984 \\
Primary inner spring & - & - & 6476 \\
Centre pivot-bowl & 10,000 & 10,000 & 10,000 \\
Side bearers & - & 350 & 500 \\
\hline
\end{tabular}

The track in the model is a 3D surface described in the fixed reference frame. The track structure can be fully rigid and described by the geometric functions with irregularities or made of rigid bodies connected with elastic and damping elements under each wheel, the track structure is moving together with the vehicle. 


\section{Simulation Analysis}

Further analysis was carried out considering the two cases of external loading. In the first case, the load is the vertical force due to the body weight, while the second case includes additional lateral force component and friction torque resulting from the dynamic effects during the curve negotiation and in the presence of lateral imperfections of the track. Due to the geometric layout of the smooth track and the travel speed, the maximum permissible unbalanced lateral acceleration (quasi-static) of the vehicle body is $0.72 \mathrm{~m} / \mathrm{s}^{2}$ [10]. Depending on the quality of track maintenance due to its geometric imperfections, the values of measured accelerations can be much higher. The standard EN 14363:2016 permits the occurrence of the maximum estimated lateral acceleration in the body of a loaded freight vehicle at the level of $2.5-3.5 \mathrm{~m} / \mathrm{s}^{2}$. These accelerations are in the form of a random signal, they cause cyclic loads in the vehicle suspension components. In this analysis, calculations were made assuming that the estimated value of unbalanced lateral acceleration could be as high as the maximum value allowed by the standard. This corresponds to a lateral inertia force which is transferred to the bogies via the bogie pivots. To assess the nature of transverse forces acting in the vehicle's pivot zone, the dynamics of the freight wagon was simulated while riding on a straight track with imperfections at a speed in the range of $40-100 \mathrm{~km} / \mathrm{h}$. Simdel's proprietary program for multibody modelling of rail vehicles was used for the simulation [17]. The following irregularities of the track were presented in Table 4:

Table 4. Track irregularities.

\begin{tabular}{ccccc}
\hline Thread Irregularity & $\begin{array}{c}\text { Lateral-Left } \\
\text { Rail }\end{array}$ & $\begin{array}{c}\text { Lateral-Right } \\
\text { Rail }\end{array}$ & $\begin{array}{c}\text { Vertical-Centre } \\
\text { Line }\end{array}$ & Cant \\
\hline Max. amplitude $(\mathrm{mm})$ & 2 & 2 & 3 & 5 \\
Std. deviation $(\mathrm{mm})$ & 0.9 & 0.9 & 1 & 1 \\
\hline
\end{tabular}

According to the UIC518 card, the above values correspond to a very good quality of track geometry. The track geometry in terms of its irregularities is presented in Figure 5. The simulation results shown in Figure 6a indicate that, despite the relatively low kinematic excitation from the track, the level of transverse interactions, transferred between the bogie pivot, the liner and the bogie frame of the loaded freight vehicle can be relatively high.

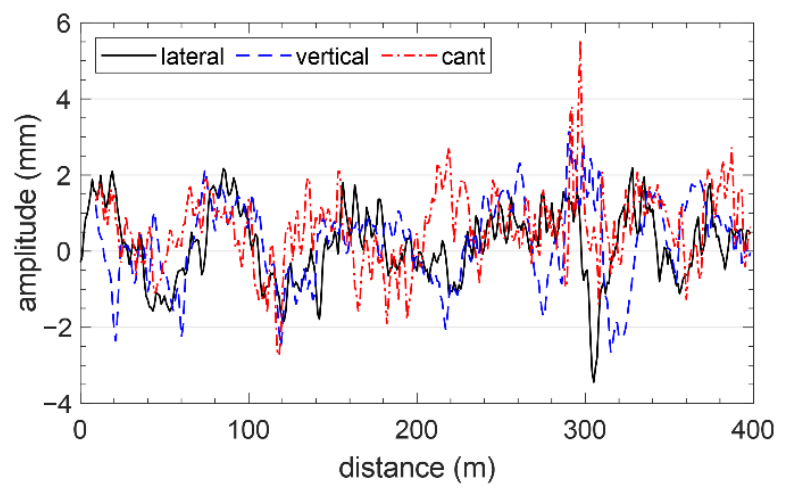

(a)

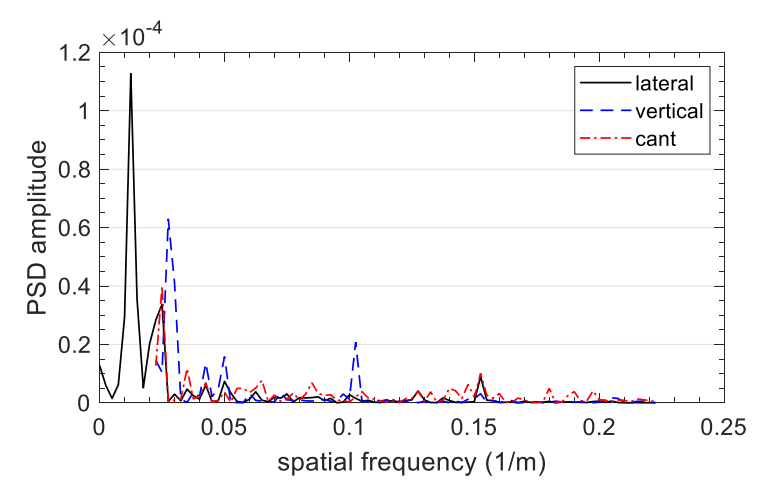

(b)

Figure 5. Track geometric irregularities (a) Power spectral density of the track irregularities (b). 


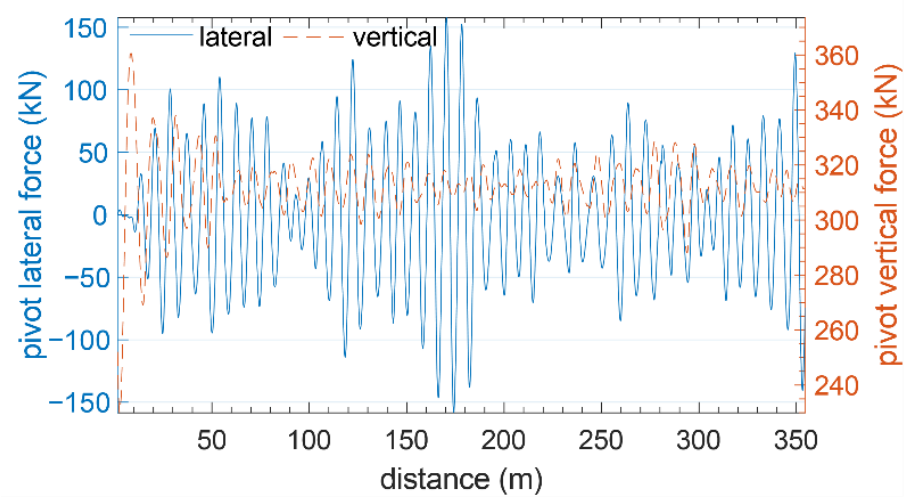

(a)

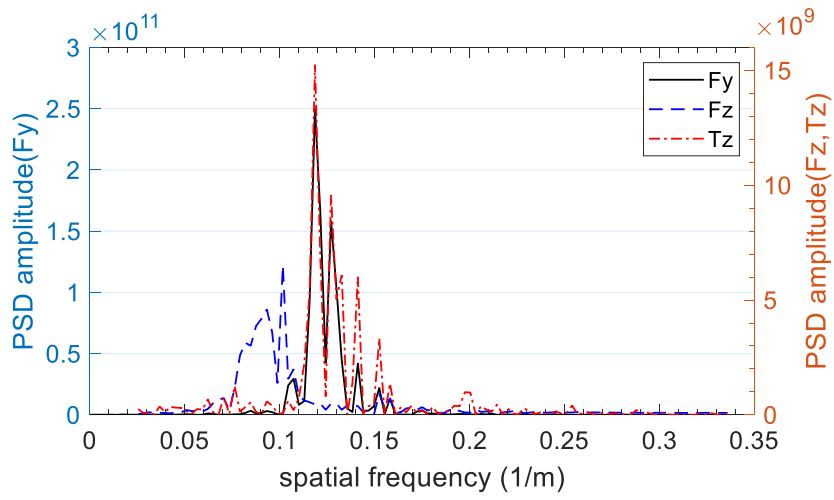

(b)

Figure 6. Lateral and longitudinal forces of interaction between the pivot and the bogie centre bowl of a loaded freight wagon $20 \mathrm{t} /$ axle while riding on a straight track with irregularities, travel speed $100 \mathrm{~km} / \mathrm{h}$ (a) Power spectral density of the interaction forces $(\mathbf{b})$.

Table 5 shows the estimated maximum value of lateral force acting between the pivot and the bogie centre bowl as a function of the vehicle speed.

Table 5. Estimated maximum lateral force between the pivot and the bogie centre bowl of the freight wagon with 20 t axle load running on the straight track with irregularities.

\begin{tabular}{ccccc}
\hline & \multicolumn{4}{c}{ Vehicle Speed $(\mathbf{k m} / \mathbf{h})$} \\
\cline { 2 - 5 } & $\mathbf{4 0}$ & $\mathbf{6 0}$ & $\mathbf{8 0}$ & $\mathbf{1 0 0}$ \\
\hline $\begin{array}{c}\text { Estimated maximum lateral } \\
\text { force (at 99.7\%) (kN) }\end{array}$ & 12.2 & 40.5 & 116.5 & 164.7 \\
\hline
\end{tabular}

In the next step, FEM was used to analyse the mechanical interactions of the friction pair of the freight wagon pivot, liner and the bogie centre bowl. Figure 7a,b present the results of the interaction effects at nominal vertical load from the fixed weight of the loaded vehicle body: on the left side, there is a total deformation of the polymer liner, while on the right the distribution of stresses according to the Huber-Mises-Hencky energy hypothesis. The distributions are symmetrical with a clearly marked concentration of interactions in the area adjacent to the outer edge and the orifice. In this area, there is a maximum stress of 27.4 MPa. Figure $7 \mathrm{~b}, \mathrm{c}$ present the results of the interaction effects due to the vertical force and the additional transverse force component of $42 \mathrm{kN}$ at velocity $60 \mathrm{~km} / \mathrm{h}$ (the vector of this force is directed to the right).

Figure 8 shows the distributions of total deformations and equivalent stresses due to vertical $(350 \mathrm{kN})$ and lateral $(42 \mathrm{kN})$ force components for the friction liner made of bronze. The results were generated assuming that the lining material is snugly fitted in the bottom part so that there is no play between the liner orifice and the seat. In the case of slight slack, e.g., due to wear of the edge of the orifice, adverse changes in the distribution of interactions and larger deformations may occur.

Using the above FEM model, a series of simulation calculations were performed, in which the following variations were considered:

- Type of material of the contacting surfaces of the friction pair; i.e., contact between the steel surface and the other material i.e., the polymer liner, the bronze and the steel surface;

- Loading scenario; vertical force from the wagon's weight as well as vertical force and additional lateral force;

- Value of the coefficient of friction; three values of the coefficient of friction were assumed: 0.1 is the typical value at the nominal state of a friction pair containing a 
polymer liner (depending on the modifiers of the liner material, the coefficient may be in the range of $0.1-0.25) ; 0.4$ is a value that can occur after a long period during normal operation; 0.6 - this is the extreme value that occurs in the case of a broken pivot connection.

The maximum equivalent stress in the liner (or the pivot) increases in value under the influence of additional lateral load, to some extent it also depends on the type of material and coefficient of friction (Figure 9). With a higher coefficient of friction, there could be larger differences between the scenarios. The additional lateral load does not significantly affect the average contact pressure, but it affects the contact geometry and variability of the pressure distribution in this zone. Because of the transverse force, the area near the edge of the orifice in which the maximum contact pressure occurs is smaller.

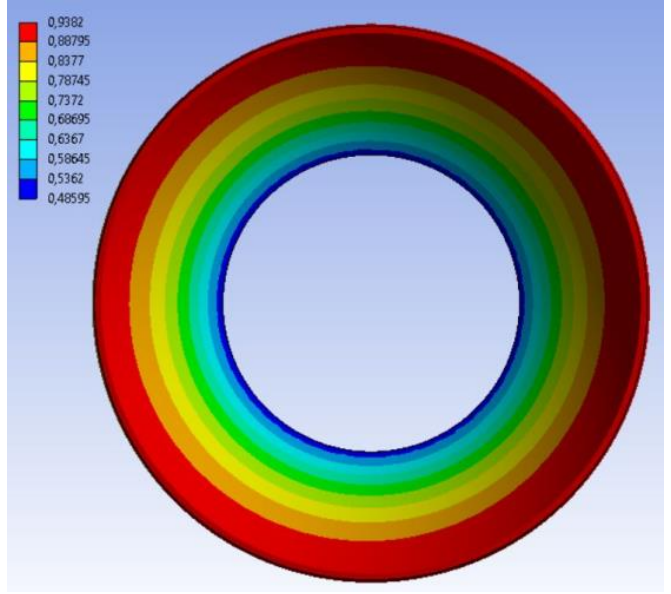

(a) total deformation (max. $0.9 \mathrm{~mm}$ )

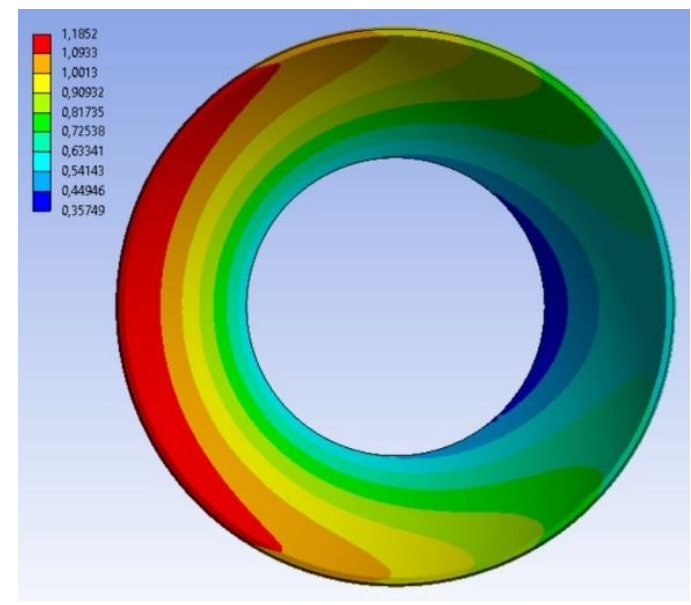

(c) total deformation (max. $1.2 \mathrm{~mm}$ )

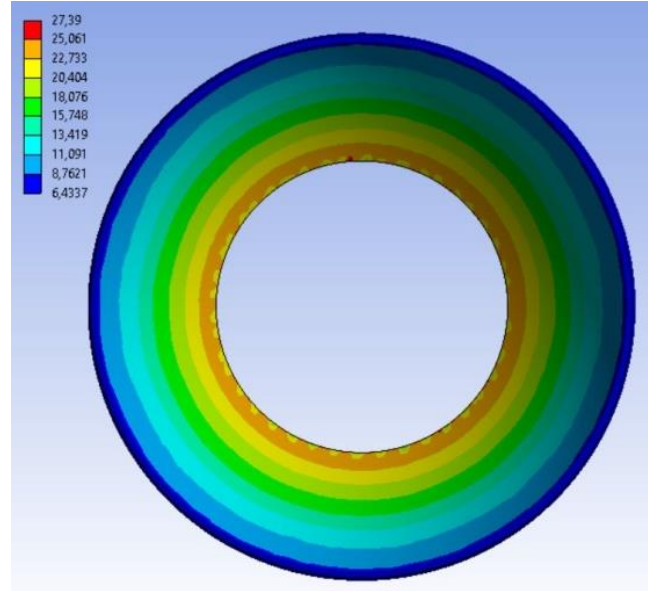

(b) equivalent stress (max. 27.4 MPa)

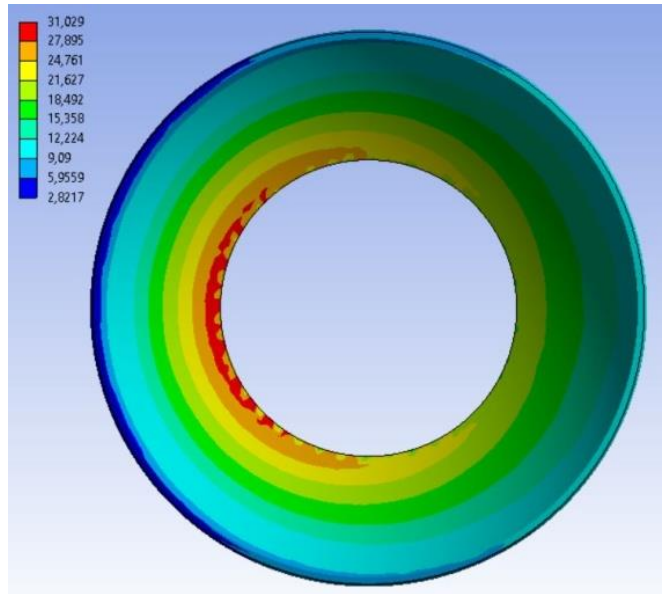

(d) equivalent stress (max. $31 \mathrm{MPa}$ )

Figure 7. Polymer liner embedded without clearance, coefficient of friction $\mu=0.1$, vertical and lateral load components: (a,b) $\mathrm{Fz}=350 \mathrm{kN}, \mathrm{Fy}=0 \mathrm{~N}$ (c,d) Fz $=350 \mathrm{kN}, \mathrm{Fy}=42 \mathrm{kN}$ (at velocity $60 \mathrm{~km} / \mathrm{h}$ ). 


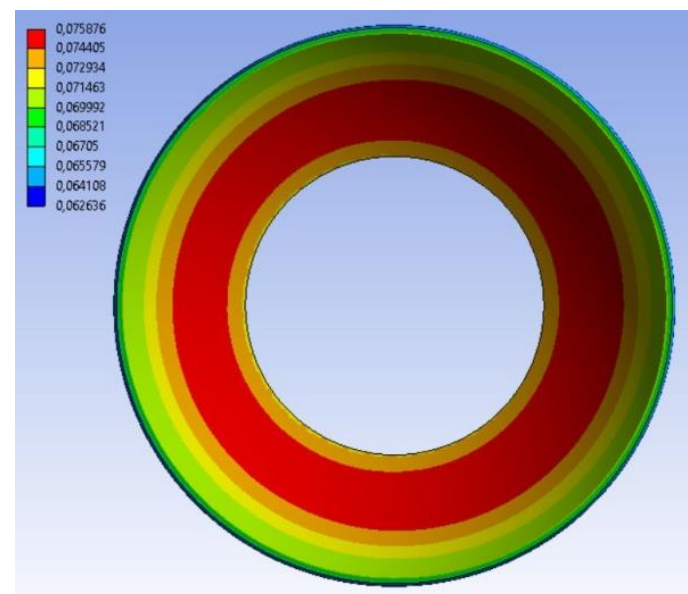

(a) total deformation (max. $0.075 \mathrm{~mm})$

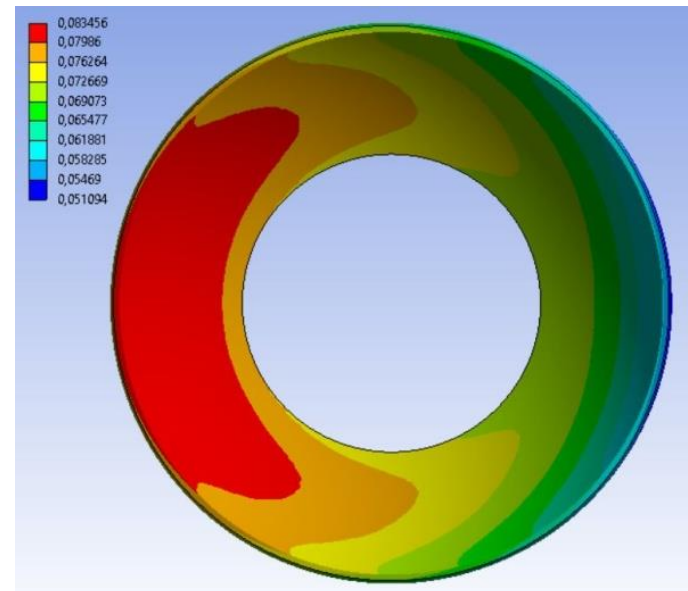

(c) total deformation (max. $0.083 \mathrm{~mm}$ )

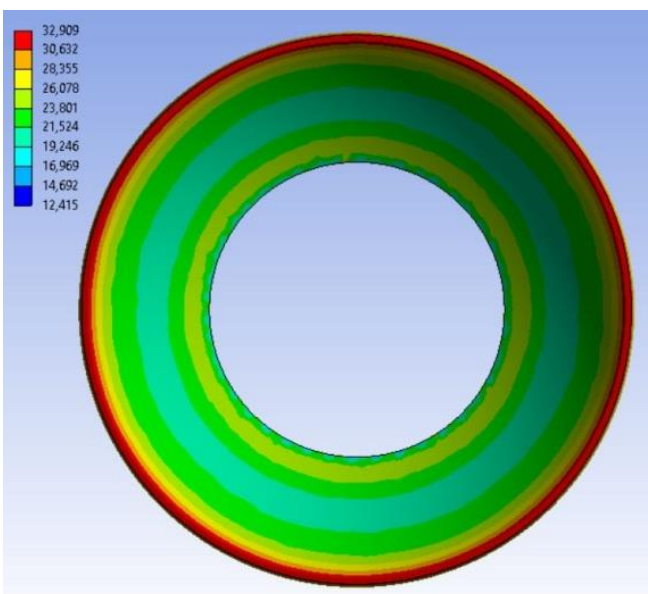

(b) equivalent stress (max. $32.9 \mathrm{MPa}$ )

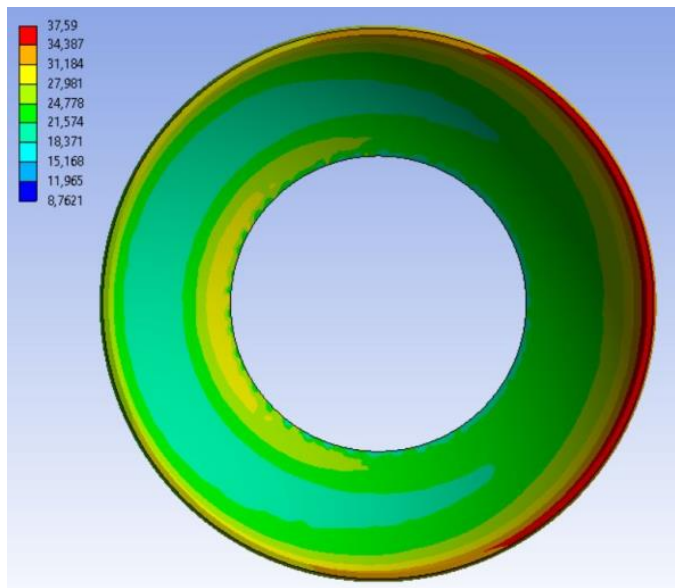

(d) equivalent stress (max. $37.6 \mathrm{MPa})$

Figure 8. Bronze liner embedded with no clearance, vertical load from the fixed weight of the loaded body, coefficient of friction $\mu=0.1$, vertical and lateral load components: (a,b) Fz $=350 \mathrm{kN}, \mathrm{Fy}=0 \mathrm{~N}$ (c,d) Fz $=350 \mathrm{kN}, \mathrm{Fy}=42 \mathrm{kN}$, (a) maximum contact pressure $17.5 \mathrm{MPa}$, (b) maximum equivalent stress $42.1 \mathrm{MPa}$.

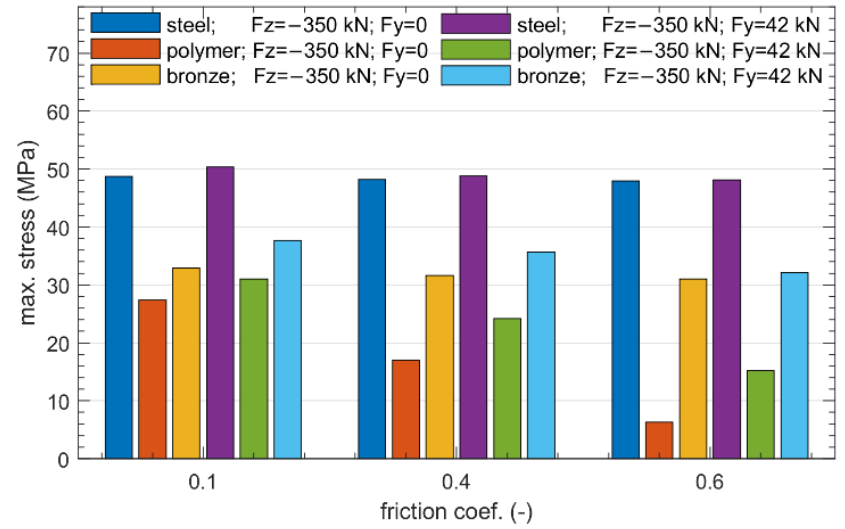

(a)

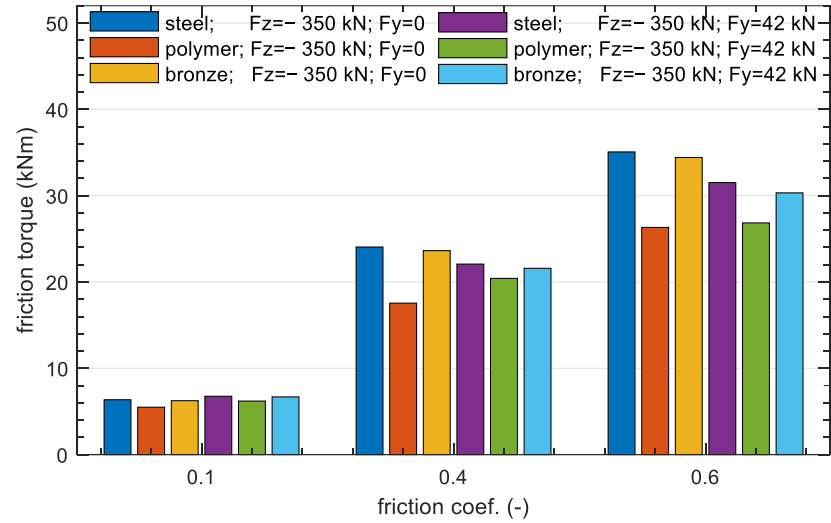

(b)

Figure 9. (a) Maximum equivalent stress values of the friction liner or pivot based on the Huber-Mises-Hencky hypothesis, (b) Values of friction torque in the centre bowl as a function of friction coefficient, type of material and lateral force value. 
The value of the frictional moment in the centre bowl is proportional to the average contact pressure, coefficient of friction and the shape factor (contact geometry). The additional lateral load resulting from the typical operating conditions of the wagon does not significantly change the frictional moment (Figure 9b).

In the presence of an additional lateral load, the area in which the contact pressure has little variation increases and the area in which there is maximum contact pressure near the edge of the orifice is decreased.

The pressure distribution is different in the case of contact between polymer liner and the other metal-metal connections.

\section{Fatigue Life Calculation}

Fatigue is a common cause of premature structural failure and therefore the term means in practice the finite number of load cycles that a material can transfer. There are many factors that directly affect this cycle limit, these include, among others, the nature of the loads, the sequence of loads and the duration of the loads. It is assumed that the maximal equivalent stress in the suspension element is a function of the wagon static load, track quality and vehicle speed:

$$
\sigma_{e q \_} m=f\left(p_{s}, q_{t}, v\right),
$$

where $p_{S}$ is freight wagon static load, $q_{t}$ is the track geometry quality according to the UIC 518 and EN 14363 (three categories of the track geometry are included: QN1, QN2, QN3, assuming the total test track length consists in sections according to the proportion: 50\% equal to QN1, 40\% between QN1 and QN2, 10\% between QN2 and QN3).

Fatigue damage (design life divided by available life) is accumulated for the representative of the several different track sections:

$$
C_{t}=\sum_{i=1}^{m} C_{s i}\left(q_{t}, v\right)
$$

where: $C_{t}$-total damage, $C_{s i}$-damage accumulated for the $i$-th track section of a given quality travelled at a given speed, $m$-number of track sections, $v$-speed.

Stress-life approach for high-cycle fatigue is assumed where the cycle counting for irregular load histories for individual track section is done with a Rainflow cycle counting method (conversion of an irregular stress history to cycles used for fatigue calculations). Damage summation for the individual track section is performed via the PalmgrenMiner rule:

$$
\mathrm{C}_{s i}=\sum_{i=1}^{k} \frac{n_{i}}{N_{f i}}
$$

where: $\mathrm{C}_{s i}$-fraction of life consumed by exposure to the cycles at the different stress levels for a given $i$-th track section, $n_{i}$ - cycles at a given stress amplitude, $N_{f i}$ - cycles to failure at a given stress amplitude.

To quantify the interaction of mean and alternating stresses on the fatigue life of the material the Goodman mean stress relation was used (no correction is done for compressive mean stresses):

$$
\frac{\sigma_{\text {alternating }}}{S_{\text {fatigue_limit }}}+\frac{\sigma_{\text {mean }}}{S_{\text {ultimate_strength }}}=1
$$

$\sigma_{\text {alternating }}$ is the equivalent fatigue limit for combined alternating and mean stress. Fatigue life properties of the materials are based on the experimental data in the form of S-N curves (Figure 10b), which can be described by the Basquin's equation in the approximate region, where $10^{3}<N<10^{6}$ :

$$
S_{f}=\mathrm{AN}_{f}^{B}
$$

where $S_{f}$-reversing stress, $A, B$-material constants, $N_{f}$-number of cycles. Presented experimental test data is uniaxial whereas the stresses are usually multiaxial. It would be 
desirable to use S-N data collected through multiaxial loading, but such tests are rarely possible due to the cost. Hence stress must be converted from a multiaxial stress state to a uniaxial one. Multiaxial failure criteria in the context of multiaxial fatigue loadings have been a subject of many studies in the last decades resulting in many multiaxial fatigue models proposed, based on different concepts: stress invariants, energy, fracture mechanics, critical plane [18]. Some of them tested in the ANSYS environment [19]. Nevertheless, gaps between the theoretical models and engineering applications still exist. In this study, the range of stresses used for fatigue analysis were calculated using a signed Tresca criterion, taking into account the value of the biaxiality factor $\alpha>0.5$ ( $\alpha$ is defined as the principal stress smaller in magnitude divided by the larger principal stress, with the principal stress nearest zero ignored).

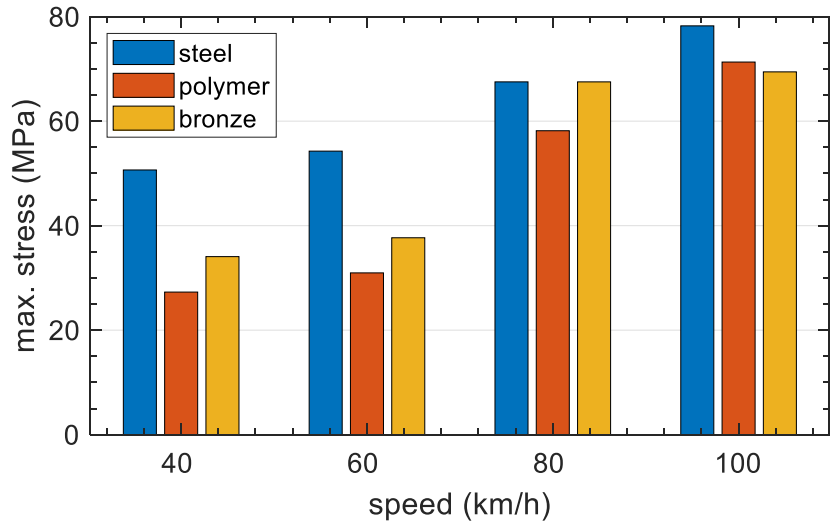

(a)

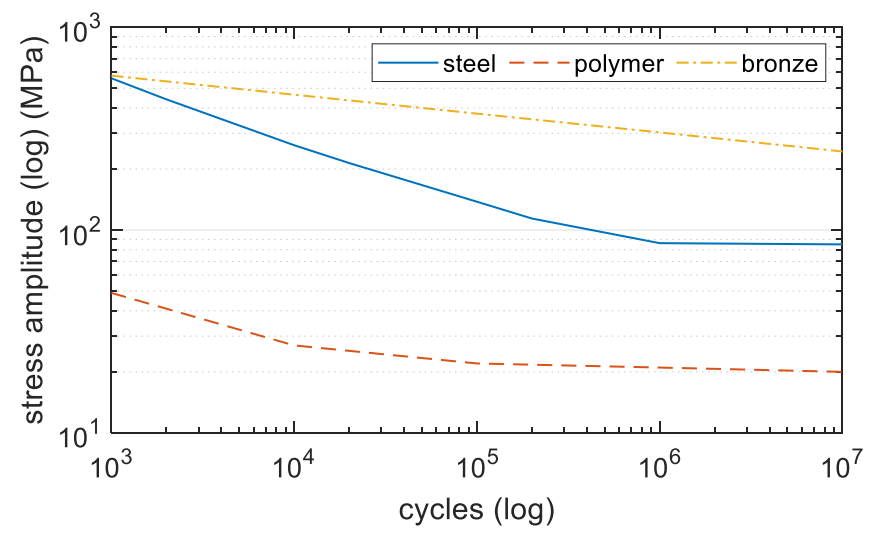

(b)

Figure 10. (a) Equivalent stress component (Huber-Mises-Hencky) (b) S-N curves based on experimental data.

Figure 10a shows the values of the equivalent stresses in the steel-steel, polymer-steel and bronze-steel contact for different vehicle speeds, the highest stresses were observed for steel-steel interactions while polymer-steel have the lowest stresses in most cases. The results of the calculated safety factors for the friction liner made of the three types of material are shown in Figure 11.

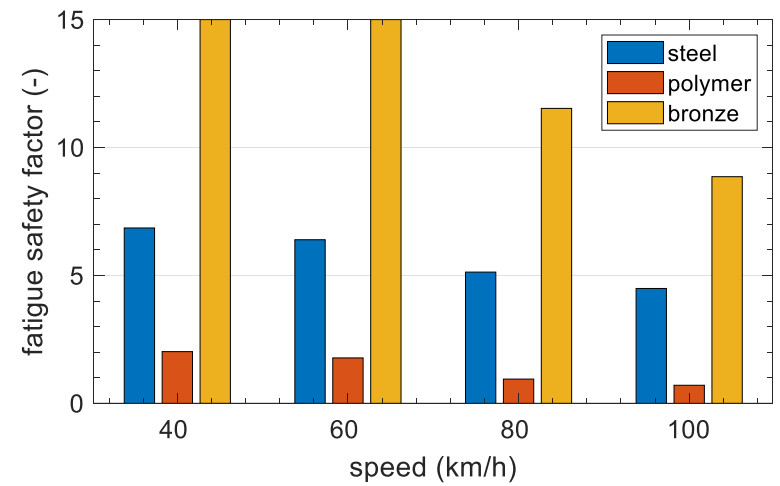

(a)

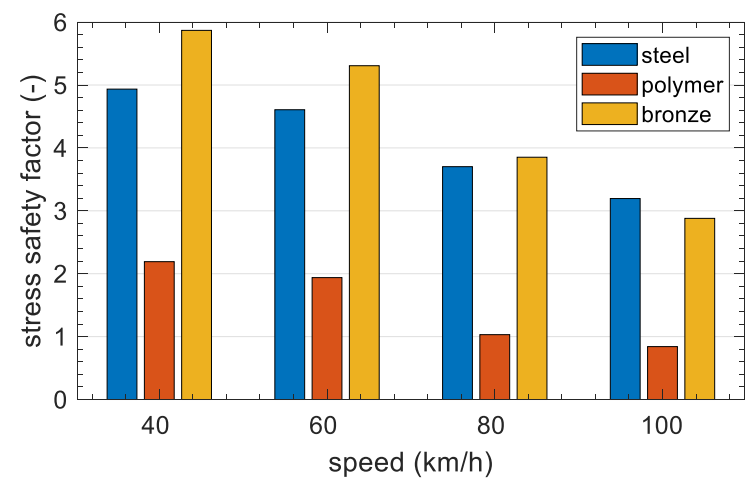

(b)

Figure 11. Calculated safety factors for the friction liner (a) fatigue safety factor-values less than 1 indicate failure before the design life is reached. Max. value $=15$ (designed life of $1 \times 10^{9}$ cycles) $(\mathbf{b})$ stress safety factor. 
Calculations are made for a designed life of $1 \times 10^{9}$ cycles, which is equivalent to a number of kilometres for a given track geometry quality. Fatigue safety factor values less than 1 indicate failure before the design life is reached. The maximum value is 15 .

\section{Conclusions}

Comparative studies were presented on the effects of the dynamics of the suspension on the multiaxial stresses in the suspension liner material using FEM and MBS simulation, considering the loads that may occur in the actual operating conditions of the vehicle. The results show the magnitude and location of the highest equivalent stresses in the liner with varying input loads as a function of the vehicle speed. Selected parameters of the suspension model were verified on the basis of a comparison with the results obtained in the bench tests of the moment of resistance of the bogie. The presented analysis is a basis for a simulation method for predicting the fatigue life of a friction liner placed in the centre bowl. The procedure of experimental tests is known in the literature [14], but there is no information about testing these types of liners during simulation studies. In the discussed case, the use of polymer, bronze and steel as a liner material was investigated. For the case of bronze, there was the highest fatigue safety factor for it at the broad range of speeds. It is not known if this type of material is used for pivot bearing liners in the freight vehicles. From the analysis of polymer liners point of view, the following advantages can be indicated:

- They do not require lubrication, what makes their operation easier;

- $\quad$ Easy to replace, inexpensive;

- Constant coefficient of friction between the bogie and the body;

- Indirect positive influence on the wear rate of the wheels and rails.

Calculated fatigue life on the basis of spectral density for a track with good condition shows a durability of 100,000 km wagon kilometrage for a cast polymer pad. The highest values of internal stresses occur in the area close to the inner edge of the liner orifice or at the outer rim of the liner.

The reliability of the friction connection between the freight wagon body and the bogie depends largely on the material from which the lining has been made, as well as on the conditions of vehicle operation such as track condition, speed, vehicle loading level, temperature. The consequences of damage to this element during operation are increased values of the forces of interaction between the vehicle and the track and the risk of derailing the vehicle. Appropriate maintenance of the technical condition of the pivot lining as a part of periodic inspections consists primarily in replacing an excessively worn liner component with a new one. Increased reliability can be obtained by examining the mechanisms that cause stress and fatigue in order to predict the useful life of this suspension part.

Author Contributions: Methodology, proprietary multibody simulation software, simulation investigation, data analysis, original draft writing, M.O.; supervision, material data, writing, J.K.; conceptualization, resources, paper preparation, S.K.; data visualization, review and editing, R.M. All authors have read and agreed to the published version of the manuscript.

Funding: Publication of this article was possible thanks to funds from the grant in the Scientific Discipline of Civil Engineering and Transport at the Warsaw University of Technology, Warsaw, Poland 2021.

Institutional Review Board Statement: Not applicable.

Informed Consent Statement: Not applicable.

Data Availability Statement: Not applicable.

Conflicts of Interest: The authors declare no conflict of interest. 


\section{References}

1. Ashby, M.F. Materials Selection in Mechanical Design, 5th ed.; Elsevier LTD.: Oxford, UK, 2016.

2. Ehrenstein, G.W.; Brocka-Krzemińska, Ż. Materiały Polimerowe. Struktura, Właściwości, Zastosowanie (Polymer Materials. Structure, Properties, Application); Wydawnictwo Naukowe PWN: Warsaw, Poland, 2014.

3. Wang, S.; Cao, B.; Niu, C.; Pan, L. Effect of Temperature on Mechanical Properties and Torsional Friction Behaviors of Bogie Center Plate. J. Tribol. 2015, 138, 011104. [CrossRef]

4. Donato, G.H.; Bianchi, M. Pressure Dependent Yield Criteria Applied for Improving Design Practices and Integrity Assessments against Yielding of Engineering Polymers. J. Mater. Res. Technol. 2012, 1, 2-7. [CrossRef]

5. Siviour, C.R.; Jordan, J.L. High Strain Rate Mechanics of Polymers: A Review. J. Dyn. Behav. Mater. 2016, 2, 15-32. [CrossRef]

6. Zhai, M.F. Vehicle-Track Coupled Dynamics, 1st ed.; Springer: Singapore, 2020.

7. Song, Y.; Wang, Z.; Liu, Z.; Wang, R. A spatial coupling model to study dynamic performance of pantograph-catenary with vehicle-track excitation. Mech. Syst. Signal Process. 2021, 151, 107336. [CrossRef]

8. Clark, G. Urgent Safety Advice; Incident report no 0776; Rail Accident Investigation Branch: Farnborough, UK, 2015.

9. Ministry of Infrastructure and Development. Regulation of the Minister of Infrastructure and Development, amending the ordinance on technical conditions to be met by railway structures and their location. In Journal of Laws of the Republic of Poland, No. 0, Item 867; Ministry of Infrastructure and Development: Warsaw, Poland, 2014. (In Polish)

10. Ministry of Infrastructure. Regulation of the Minister of Infrastructure regarding the scope of examinations necessary to obtain certificates for placing in service of types of buildings and devices intended for railway traffic and types of railway vehicles. In Journal of Laws of the Republic of Poland, No. 212, Item 1772; Ministry of Infrastructure: Warsaw, Poland, 2005. (In Polish)

11. International Union of Railways (UIC). UIC 510-1. In Wagons-Running Gear-Normalisation, 9th ed.; of 1.1.78 and 14 Amendments; International Union of Railways (UIC): Paris, France, 2004.

12. European Committee for Standardization. EN 14363:2016. In Railway Applications-Testing and Simulation for the Acceptance of Running Characteristics of Railway Vehicles. Running Behaviour and Stationary Tests; European Committee for Standardization: Brussels, Belgium, 2016.

13. Official Journal of the European Union. Commission Regulation (EU) No 321/2013 of 13 March 2013 Concerning the Technical Specification for Interoperability Relating to the Subsystem 'Rolling Stock-Freight Wagons' of the Rail System in the European Union; Official Journal of the European Union: Luxembourg, 2013.

14. European Rail Research Institute. ERRI B12/RP17. In Programme of Tests to Be Carried out on Wagons with Steel Underframe and Body Structure (Suitable for Being Fitted with the Automatic Buffing and Draw Coupler) and on Their Cast Steel Frame Bogies, 8th ed.; European Rail Research Institute: Utrecht, The Netherlands, 1997.

15. Fergusson, S.N.; Fröhling, R.D.; Klopper, H. Minimising wheel wear by optimising the primary suspension stiffness and centre plate friction of self-steering bogies. Veh. Syst. Dyn. 2008, 46, 457-468. [CrossRef]

16. Wu, H.; Robeda, J. Effects of bogie center plate lubrication on vehicle curving and lateral stability. Veh. Syst. Dyn. 2004, 41, 292-302.

17. Opala, M. Evaluation of bogie centre bowl friction models in the context of safety against derailment simulation predictions. Arch. Appl. Mech. 2018, 88, 943-953. [CrossRef]

18. Engin, Z.; Coker, D. Comparison of Equivalent Stress Methods with Critical Plane Approaches for Multiaxial High Cycle Fatigue Assessment. Procedia Struct. Integr. 2017, 5, 1229-1236. [CrossRef]

19. Sun, G.-Q.; Shang, D.-G. Prediction of fatigue lifetime under multiaxial cyclic loading using finite element analysis. Mater. Des. 2010, 31, 126-133. [CrossRef] 